\title{
New fluorescein precursors for live bacteria detection
}

\author{
Celia GUILINI ${ }^{1}$, Corinne BAEHR ${ }^{2 \#}$, Etienne SCHAEFFER ${ }^{1 \#}$, Patrick GIZZI $^{1}$, Frédéric RUFI ${ }^{3}$, Jacques \\ HAIECH $^{2}$, Etienne WEISS ${ }^{1}$, Dominique BONNET ${ }^{2}$, Jean-Luc GALZI ${ }^{1}$
}

${ }^{1}$ Biotechnologie et Signalisation Cellulaire, UMR 7242 CNRS/Université de Strasbourg, and Labex Medalis, ESBS, 300 Boulevard Sébastien Brant, 67412 Illkirch, France

${ }^{2}$ Laboratoire d'Innovation Thérapeutique, UMR 7200 CNRS/Université de Strasbourg, and Labex Medalis,

Faculté de Pharmacie, 74 route du Rhin, 67401 Illkirch, France

${ }^{3}$ Bürkert Fluid control systems, BP21, 67220 Triembach-au-Val, France

${ }^{\#}$ These authors contributed equally to the work

\begin{abstract}
Swiftness, reliability and sensitivity of live bacteria detection in drinking water are key issues for human safety. The most widespread used indicator of live bacteria is a caged form of carboxyfluorescein in which 3' and 6' hydroxyl groups are masked as acetate esters (CFDA). This derivatization altogether abolishes fluorescein fluorescence and renders the molecule prone to passive diffusion through bacterial membranes. Once in the cytoplasm, acetate groups from CFDA are removed by bacterial hydrolases and fluorescence develops, rendering

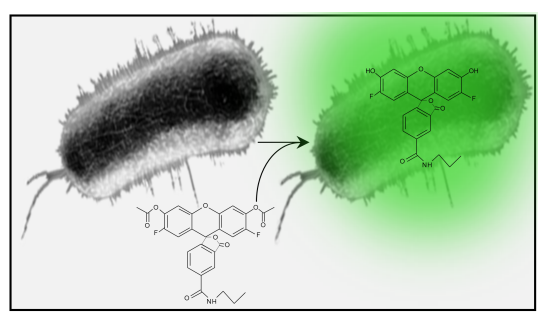
live, but not dead cells detectable. Yet the reagent, carboxyfluorescein di-acetate, still possesses a free carboxyl group whose ionization constant is such that the majority of the probe is charged at physiological $\mathrm{pH}$. This unfavors probe permeation through membranes. Here, we prepare several chemical modifications of the carboxyl moiety of CFDA, in order to neutralize its charge and improve its passive diffusion through membranes. We show that ethylamido derivative of the 5-carboxyl group from 5-carboxy-fluorescein diacetate or from Oregon green diacetate or from Oregon green di-acetoxymethylester are stable molecules in biological media and penetrate into bacterial cells and are metabolized into fluorescent species. Only live bacteria are revealed since bleached samples are not labelled. Other derivations of the 5-carboxyl group such as with an ester group or a thiourea-based moiety were almost inefficient probes. The most interesting probe, triembarine (5ethylaminocarboxy- oregon green, 3', 6'diacetoxymethyl ester) leads to 6-10 more sensitive detection of bacteria as compared to CFDA. Addition of contrast agents (trypan blue or brilliant blue R) improve the signal to noise ratio by quenching extracellular fluorescence while bromophenol blue quenches both intracellular and extracellular fluorescence, allowing standardization of detections.
\end{abstract}

\section{Introduction}

Microorganisms are vastly present in drinking water ${ }^{1}$, mostly living on the pipe surface of water distribution systems ${ }^{2}$. As the majority of water-living microorganisms are not pathogenic to humans, research on bacteria causing diseases is restricted to few species. These are only found in contaminated waters, and their presence is directly correlated to disease development ${ }^{3}$. When present in a growth-promoting medium, most of these pathogenic bacteria have a short duplication time, making them threatening human health. Preventing epidemics requires fast and sensitive bacterial detection (being able to detect one bacterium in large volumes of water).

Different techniques have been developed to identify most common pathogens in drinking water. Leading techniques in the field are based on modified carbon sources that are assimilated by bacteria and serve as probes 
to reveal their presence. The carbon sources are for instance sugars linked to reporter groups, either dyes or fluorogenic compounds, which are metabolized by living bacteria, releasing the activated reporter moiety. A routinely used system for coliform bacteria detection (Colilert-18 ${ }^{\circledR}$ from Idexx ${ }^{\circledR}$ ) is based on 4Methylumbelliferyl- $\beta$-D-glucuronide (MUG) and Ortho-nitrophényl- $\beta$-galactoside (ONPG). MUG is cleaved by the E.coli $\beta$-D-glucuronidase to form glucuronic acid and the fluorescent methyl umbelliferon. ONPG is cleaved by coliforms $\beta$-galactosidase into galactose and yellow orthonitrophenol), which is suitable for the detection of one bacterium in $100 \mathrm{~mL}$ of drinking water after 18 hour growth.

A second system $\left(\right.$ Chromocult $^{\circledR}$ from Millipore ${ }^{\circledR}$ ) uses filters to concentrate bacteria and selective overnight growth with color coded detection of contaminating species. Although these methods are extremely powerful, they need overnight incubation, a period of time during which there is no alert to avoid population threat.

Automated repeated measurements would be an alternative to current methods in order to provide investigatorindependent evaluation of water quality control.

Currently approaches use pro-fluorophores capable to penetrate into bacterial cytoplasm and get converted into detectable fluorescent compounds by host organism esterases. Among the molecules that are best described and most adapted for this application is carboxyfluorescein derived probes: 5-Carboxyfluorescein and its 2',7'bisfluoro derivative, Oregon green ${ }^{\circledR}$. They are used as acetates or acetoxymethyl esters hiding the hydroxyl groups at positions $3^{\prime}$ and $6^{\prime}$ in order to favour cell penetration. Living bacteria are able to cleave that groups and thus lead to living bacteria detection while dead bacteria are not.

However, these molecules do have a free carboxylic acid group that remains unprotected. The negatively charged carboxylate is largely ionized at physiologic $\mathrm{pH}$ therefore limiting diffusion through bacterial membranes. We hypothesized that pro-fluorophores in which the carboxylate function is masked would confer better passive diffusion properties and would improve bacteria brightness and thus sensitivity of the detection. In this work, we investigated whether chemical modifications of the free carboxylate group from carboxyfluorescein and Oregon green that may improve fluorophore uptake and thus detection of live bacteria in aqueous media. We identified a molecule, named Triembarine, which fulfils the criteria and allows a 6-10 fold increase in detection sensitivity. Combined with non-carcinogenic, mutagenic or reprotoxic (CMR) contrast agents as quenchers, signal to noise ratio was significantly improved. 


\section{Materials and methods}

\section{Bacterial strains}

Escherichia coli (E. coli) (ATCC 8739) and Bacillus subtilis (B. subtilis) (ATCC 6633) strains were routinely grown in Luria Bertani (LB) broth (Sigma-Aldrich, L3022) or on LB agar plates (Sigma-Aldrich, L2897) for 18h at $37{ }^{\circ} \mathrm{C}$. Waterborne environmental bacteria such as Enterobacter cloacae (E. cloacae), Chryseobacterium indologenes (C. indologenes), Pseudomonas aeruginosa ( $P$. aeruginosa), and E. coli (EC18) were provided by Eurofins company. Environmental bacteria were grown in LB broth or on casein-peptone soymeal-peptone agar (CASO agar) plates (Merck Millipore, 105458) for $18 \mathrm{~h}$ at $37^{\circ} \mathrm{C}$.

\section{Synthesis of pro-fluorescent probes derived from fluorescein and Oregon Green}

Reagents were obtained from commercial sources and used without further purification. Starting fluorophores were obtained from commercial sources: 5-carboxyfluorescein succinimidyl ester and Oregon Green ${ }^{\circledR} 488$ carboxylic acid from Life Technologies, fluorescein isothiocyanate isomer I from Sigma Aldrich and 5,6carboxyfluorescein from Kodak. Semi preparative reverse-phase high performance liquid chromatography (RPHPLC) separations were performed on a $\mathrm{C}_{18}$ Waters SunFire ${ }^{\mathrm{TM}}$ Prep C18 OBD $^{\mathrm{TM}}(5 \mu \mathrm{m}, 19 \mathrm{~mm} \times 150 \mathrm{~mm})$ using a linear gradient of solvent B in solvent A $5 \%$ to $100 \%$; solvent A: water with $0.1 \%$ trifluoroacetic acid (TFA); solvent B: acetonitrile with $0.1 \%$ TFA; over $60 \mathrm{~min}$ for 5-PITCFDA and $25 \mathrm{~min}$ for the other compounds; flow rate of $20 \mathrm{~mL} \cdot \mathrm{min}^{-1}$; detection at $220 \mathrm{~nm}$ and $254 \mathrm{~nm}$. Analytical RP-HPLC separations were performed on a $\mathrm{C} 18$ Supelco Ascentis ${ }^{\circledR}$ Express $(2.7 \mu \mathrm{m}, 4.6 \mathrm{~mm} \times 75 \mathrm{~mm})$ using a linear gradient $(5 \%$ to $100 \%$ of solvent B in solvent A in $7.5 \mathrm{~min}$, flow rate of $1.6 \mathrm{~mL} \cdot \mathrm{min}^{-1}$, detection at $220 \mathrm{~nm}$ and $254 \mathrm{~nm}$, solvent A: water with $0.1 \%$ TFA, solvent B: acetonitrile with $0.1 \%$ TFA). Purified final compounds eluted as single and symmetrical peaks at retention times $\left(t_{\mathrm{R}}\right)$ given below. Their identity was determined by high resolution mass spectroscopy (HRMS) which were acquired on an Agilent Technology 6520 QTof LC/MS mass spectrometer. Intermediates were analysed by liquid chromatography mass spectroscopy (LCMS) which were acquired on an Agilent LC-MSD 1200SL, using a multi-mode MM-ES+APCI source. All chemical analyses are given in supplementary information section

1-(3',6'-dihydroxy-3-oxo-3H-spiro[isobenzofuran-1,9'-xanthen]-5-yl)-3-propylthiourea (5-PFT): To a solution of fluorescein-5-isothiocyanate $(10 \mathrm{mg}, 25 \mu \mathrm{mol})$ in anhydrous DMSO $(5 \mathrm{~mL})$ were added N,N-diisopropylethylamine (DIEA) $(25 \mu \mathrm{L}, 154 \mu \mathrm{mol})$ and propylamine $(4.2 \mu \mathrm{L}, 51 \mu \mathrm{mol})$. The reaction mixture was stirred overnight in the dark, at room temperature and freeze-dried to afford the compound as an orange oil. The crude 
product was used in the next step without further purification. $t_{R}=4.10 \mathrm{~min}, \mathrm{RP}-\mathrm{HPLC}$ purity $>90 \%$, MS (ESI) $\mathrm{m} / \mathrm{z}: 449.0(\mathrm{M}+\mathrm{H})^{+}$

2',7'-difluoro-3',6'-dihydroxy-3-oxo-N-propyl-3H-spiro[isobenzofuran-1,9'-xanthene]-5-carboxamide

(Triembarine): To a solution of Oregon Green ${ }^{\circledR} 488$ carboxylic acid, succinimidyl ester, isomer 5 (4 mg, 7.8 $\mu \mathrm{mol})$ in anhydrous DMSO $(2.5 \mathrm{~mL})$ were added N,N-diisopropylethylamine (DIEA) $(7.8 \mu \mathrm{L}, 47 \mu \mathrm{mol})$ and propylamine $(2 \mu \mathrm{L}, 23.5 \mu \mathrm{mol})$. The reaction mixture was stirred, in the dark, overnight at room temperature and freeze-dried to afford the compound as an orange oil. The crude product was used in the next step without further purification.

3',6'-dihydroxy-3-oxo-N-propyl-3H-spiro[isobenzofuran-1,9'-xanthene]-5-carboxamide (5-PFA): To a solution of 5-carboxyfluorescein, succinimidyl ester $(5 \mathrm{mg}, 10.5 \mu \mathrm{mol})$ in anhydrous DMSO $(2.5 \mathrm{~mL})$ were added DIEA $(10 \mu \mathrm{L}, 64 \mu \mathrm{mol})$ and propylamine $(2.6 \mu \mathrm{L}, 31.7 \mu \mathrm{mol})$. The reaction mixture was stirred, in the dark, overnight at room temperature and freeze-dried to afford the compound as an orange oil. The crude product was used in the next step without further purification.

Propyl-3',6'-dihydroxy-3-oxo-3H-spiro[isobenzofuran-1,9'-xanthene]-5-carboxylate \& propyl-3',6'-dihydroxy-3oxo-3H-spiro[isobenzofuran-1,9'-xanthene]-6-carboxylate (5,6-PEF): To a solution of 5,6-carboxyfluorescein $(25 \mathrm{mg}, 66 \mu \mathrm{mol})$ in anhydrous DMF $(1 \mathrm{~mL})$ were added DIEA $(33 \mu \mathrm{L}, 0.2 \mathrm{mmol})$ and 1-bromopropane $(12 \mu \mathrm{L}$, $0.13 \mathrm{mmol}$ ). The reaction mixture was stirred at $35^{\circ} \mathrm{C}$, in the dark, for $48 \mathrm{~h}$ and purified by reverse-phase HPLC to afford isomer $5(10.7 \mathrm{mg}, 38 \%)$ and isomer $6(9.6 \mathrm{mg}, 35 \%)$ as orange solids.

\section{General procedure for acetylation}

To a solution of a 3',6'-dihydroxy-xantene (10 $\mu \mathrm{mol}, 1$ equiv) in a mixture of anhydrous $\mathrm{CH}_{2} \mathrm{Cl}_{2} / \mathrm{DMF}(2.4$ $\mathrm{mL}, 5 / 1)$ were added pyridine $(0.52 \mathrm{mmol}, 60$ equiv) and acetic anhydride ( $0.63 \mathrm{mmol}, 50$ equiv). The reaction mixture was stirred, in the dark, at $\mathrm{rt}$ for $4 \mathrm{~h}$. All compounds were isolated by reverse-phase HPLC to give the targeted products $(18-83 \%)$.

2',7'-difluoro-3-oxo-5-(propylcarbamoyl)-3H-spiro[isobenzofuran-1,9'-xanthene]-3',6'-diyl diacetoxymethyl ester (Triembarine AM): Triembarine $(8.8 \mathrm{mg}, 0.019 \mathrm{mmol})$, powdered 4- $\AA$ molecular sieves $(10 \mathrm{mg})$, and Ag2O (11 mg, $0.048 \mathrm{mmol})$ were suspended in anhydrous $\mathrm{CH} 3 \mathrm{CN}(0.5 \mathrm{~mL})$ under argon. Bromomethyl acetate (7.6 $\mu \mathrm{L}, 0.077 \mathrm{mmol}$ ) was added, and the reaction mixture was stirred for $48 \mathrm{~h}$. The reaction mixture was then filtered through a pad of celite. The solution was concentrated under reduced pressure. A first purification by 
reverse-phase HPLC and then via column chromatography (silica gel, 5 to 20\% EtOAc in $\mathrm{CH} 2 \mathrm{Cl} 2$ ) gives the desired product as a white solid $(4.8 \mathrm{mg}, 41 \%)$.

\section{Chemical stability}

Each pro-fluorophore (5-CFDA, 5-PFDAE, 5-PFDAT, 5-PFDA, 5-COGDA, Triembarine DA, Triembarine AM) was disolved in dimethylsulfoxide (DMSO) in order to have $10 \mathrm{mM}$ stock solution. Short-term stability studies (0-60 min) were performed in darkness at $37^{\circ} \mathrm{C}$. The pro-fluorophore stock solutions were diluted into PBS solution containing $0.6 \%$ of glutaraldehyde $(\mathrm{pH} \sim 7)$. The pro-fuorophore final concentration was $15 \mu \mathrm{M}$. Samples were in fluorescence grade quartz cuvette having a volume of $1 \mathrm{~mL}$ and every 10 minutes, fluorescence emission spectra were recorded (between 500 and $540 \mathrm{~nm}$ ). The excitation wavelength used was $488 \mathrm{~nm}$. Fluorometric measurement were made with FluoroLog®-3 (Horiba Jobin Yvon) spectrofluorometer equipped with sample stirring. Same experiment was repeated three times $(n=3)$

Long-term stability studies ( $>1$ day) were performed at room temperature $\left(23 \pm 2{ }^{\circ} \mathrm{C}\right)$ in darkness. Triembarine DA or AM $(120 \mu \mathrm{M})$ were stored in anhydrous DMSO (Sigma-Aldrich, 276855). The solution of 5-CFDA (20 $\mu \mathrm{M})$ in acetonitrile stored at $-80{ }^{\circ} \mathrm{C}$ was used as internal reference for HPLC-MS/MS analyses. The solution injected was composed of Triembarine DA or AM $(1.2 \mu \mathrm{M})$, 5-CFDA $(0,2 \mu \mathrm{M})$ in $\mathrm{H}_{2} \mathrm{O} /$ acetonitrile ratio $1 / 1$ (V/V). Long-term stability studies were performed using an UHPLC-MS/MS system (LC-MS 8030, Shimadzu). Data acquisition and analysis were performed using LabSolutions version 5 software. Measurements were carried out at $40^{\circ} \mathrm{C}$. A $1.7 \mu \mathrm{m}$ Kinetex column $(50 \mathrm{X} 2.1 \mathrm{~mm})$ purchased from Phenomenex was used. The mobile phase flow rate was fixed at $0.5 \mathrm{~mL} / \mathrm{min}$ and the following program was applied for the elution: $0-1.2$ $\min , 5-95 \% \mathrm{~B}$; 1.2-1.4 $\min , 95 \% \mathrm{~B}$; 1.4-1.42 $\mathrm{min}, 95-0 \% \mathrm{~B}$ and 1.42-2.8 min, 5\% B. Solvent A consisted of $0.05 \%$ formic acid in water and solvent B was HPLC grade acetonitrile. $1 \mu \mathrm{L}$ was injected. The mass spectrometer was interfaced with the UHPLC system using an electrospray ion source. The instrumental parameters were as follows: nebulizer gas, $2 \mathrm{~L} / \mathrm{min}$; DL temperature, $250^{\circ} \mathrm{C}$; block heater temperature, $400^{\circ} \mathrm{C}$; interface voltage, $4.5 \mathrm{kV}$; collision energy, between -12 and $-22 \mathrm{~V}$. The collision gas used was argon at $230 \mathrm{kPa}$. The MRM transitions were $\mathrm{m} / \mathrm{z} 598.2 \rightarrow 454.1,538.1 \rightarrow 454.1$ and $454.1 \rightarrow 368.0$, respectively for Triembarine-AM, Triembarine-DA and Triembarine. The dwell time was set to $30 \mathrm{msec}$ and the pause time to 3 msec. The percentage of remaining test compound relative to $t_{0}$ was measured by monitoring the peak area on the chromatogram. 


\section{Bacteria staining}

E. coli (ATCC 8739 or EC18), E. cloacae, C. indologenes, P. aeruginosa and B. subtilis were cultivated in Luria-Bertani (LB) broth until exponential phase at $37^{\circ} \mathrm{C}$ with shaking at $300 \mathrm{rpm}$ revolutions per minutes (rpm). Bacteria were harvested and washed in sterile phosphate buffer saline solution (PBS) (pH $~ 7.4)$ by centrifugation at $10000 \mathrm{rpm}$ for $3 \mathrm{~min}$ at room temperature $\left(23 \pm 2{ }^{\circ} \mathrm{C}\right)$. Then bacteria were resuspended in PBS at a concentration of $1 \times 10^{9}$ bacteria / mL. Bacteria concentration was calculated according to absorbance measure at $600 \mathrm{~nm}\left(\mathrm{~A}_{600 \mathrm{~nm}}=1\right.$ correspond to bacterial suspension at $\sim 5.10^{8}$ bacteria $\left./ \mathrm{mL}\right)$. Dead bacterial suspensions at $1 \times 10^{9}$ bacteria / $\mathrm{mL}$ (negative controls) of these five species of bacteria were prepared individually by addition of $20 \mu \mathrm{L}$ of bleach containing $2.6 \%$ active chlorine. Bacteria were treated with bleach solution for $15 \mathrm{~min}$. Dead bacteria were washed twice in sterile PBS by centrifugation at $10000 \mathrm{rpm}$ for $3 \mathrm{~min}$ at room temperature. The culturability of the negative controls was assessed by plating $100 \mu \mathrm{L}$ of bacterial suspension onto LB agar or Caso agar and incubating the plates at $37{ }^{\circ} \mathrm{C}$ for $72 \mathrm{~h}$. None of the negative controls displayed any growth activity. Bacteria $\left(100 \mu \mathrm{L}\right.$ suspension at $1 \times 10^{9}$ bacteria $\left./ \mathrm{mL}\right)$ were stained with $10 \mu \mathrm{M}$ or $15 \mu \mathrm{M}$ of profluorophore (5-CFDA or 5-PFDAE or 5-PFDTA or 5-PFDA or 5-COGDA or Triembarine DA or Triembarine $\mathrm{AM}$ ) in $200 \mu \mathrm{L}$ of PBS solution containing $0.6 \%$ of glutaraldehyde. Bacteria were incubated at $37^{\circ} \mathrm{C}$ for $10-60$ min with pro-fluorophore in darkness. After bacterial staining, they were washed and resuspended in $100 \mu \mathrm{L}$ of PBS as described above. Staining bacterial suspension was observed under a fluorescent microscope. These bacteria were imaged with a Leica DM5500 microscope equipped with FITC filter. Bright field images indicated that bacteria appeared to have normal physiology. Images were collected with a 100x objective. Fluorescence intensity of staining bacterial suspension was also measured with FluoroLog®-3 (Horiba Jobin-Yvon) spectrofluorometer equipped with sample stirring. Samples were in fluorescence grade quartz cuvette having a volume of $1 \mathrm{~mL}$. The excitation wavelength used was $488 \mathrm{~nm}$ and emission wavelength used was $517 \mathrm{~nm}$. Same experiment was repeated three times $(n=3)$

\section{Immunofluorescence and viability staining of E. coli}

Environmental E. coli (EC18) were cultivated and resuspended in PBS as describe above. Dead bacterial suspension was prepared as previously described. Dead or viable E. coli (EC18) (100 $\mu \mathrm{L}$ of suspension at $1 \times 10^{9}$ bacteria / $\mathrm{mL}$ ) were incubated with rabbit anti-EC18 polyclonal antibodies (anti-EC18 pAb) (dilution 1/20) for 1 $\mathrm{h}$ at room temperature. This anti-EC18 $\mathrm{pAb}$ was obtained from immunized rabbit with inactivated EC18 (Eurogentec). Bacteria were washed in PBS by centrifugation at $10000 \mathrm{rpm}$ for $3 \mathrm{~min}$ at room temperature. Then, they were resuspended in $200 \mu \mathrm{L}$ of PBS solution containing $0.6 \%$ of glutaraldehyde with $15 \mu \mathrm{M}$ of Triembarine DA and incubated for $30 \mathrm{~min}$ at $37^{\circ} \mathrm{C}$ in the dark. Following several washes with PBS as described 
above, dead or viable E. coli (EC18) were resuspended in $200 \mu \mathrm{L}$ of PBS and incubated for $1 \mathrm{~h}$ at room temperature in darkness with AlexaFluor 568 labeled-anti-rabbit immunoglobulin (dilution 1/1000) (Molecular probes, A11036). Bacteria were washed twice and resuspended in $100 \mu \mathrm{L}$ of PBS. They were imaged with a Leica DM5500 microscope equipped with FITC and Cy3 filters. Images were collected with a 100x objective. Same experiment was repeated three times $(n=3)$

\section{E. coli immobilization on Protein G Sepharose beads}

Environmental E. coli (EC18) were cultivated and resuspended in PBS as previously described. On the one hand, E. coli $(\mathrm{EC} 18)\left(100 \mu \mathrm{L}\right.$ of suspension at $1 \times 10^{9}$ bacteria $\left./ \mathrm{mL}\right)$ were incubated with rabbit anti-EC18 polyclonal antibodies (anti-EC18 pAb) or pre-immune control rabbit serum without anti-EC18 antibodies (PI-pAb) (dilution 1/20) for $1 \mathrm{~h}$ at room temperature. This control rabbit serum (PI-pAb) was obtained from a non-immunized animal (Eurogentec). It is used as a negative control. Bacteria were washed thrice in PBS by centrifugation at $10000 \mathrm{rpm}$ for $3 \mathrm{~min}$ at room temperature. On the other hand, Protein G Sepharose 4 Fast Flow beads (GE Healthcare, 17-0618-01) were washed three times in Milli-Q water and three times in PBS by centrifugation at $2000 \mathrm{rpm}$ for $2 \mathrm{~min}$ at $4{ }^{\circ} \mathrm{C}$. Then $10 \mu \mathrm{L}$ of sedimented beads were incubated with $20 \mu \mathrm{g}$ of secondary antibody goat-anti-rabbit immunoglobulin (Thermo Scientific Pierce, 31210) in $500 \mu \mathrm{L}$ of PBS with $0.001 \%$ of NP40 for $1 \mathrm{~h}$ at room temperature with gentle mixing on a wheel. After two washes with PBS, these $10 \mu \mathrm{L}$ of sedimented Protein G Sepharose beads coated with goat-anti-rabbit immunoglobulins were incubated with E. coli $(100 \mu \mathrm{L}$ of suspension at $1 \times 10^{9}$ bacteria $/ \mathrm{mL}$ ) coated with rabbit anti-EC18 antibodies in $400 \mu \mathrm{L}$ of PBS with $0.001 \%$ of NP40 for $2 \mathrm{~h}$ at room temperature with gentle mixing on a wheel. After several washes, bacteria immobilized on sedimented beads were stained with $10 \mu \mathrm{M}$ 5-CFDA or Triembarine DA or Triembarine AM in $200 \mu \mathrm{L}$ of PBS and $0.6 \%$ glutaraldehyde for $30 \mathrm{~min}$ at $37{ }^{\circ} \mathrm{C}$ in darkness. Beads were washed twice and $50 \mu \mathrm{L}$ of trypan blue solution $(0.4 \%)$ or bromophenol blue $(0.25 \%)$ or brilliant blue $\mathrm{R}(0.35 \%)$ was added. Beads were imaged with a Leica DM5500 microscope equipped with FITC filters. Images were collected with a 63x objective.

\section{Results}

Design and synthesis of pro-fluorescent probes derived from fluorescein and Oregon Green

The 5- or 6-carboxylate function of carboxyfluorescein is in equilibrium with its carboxylic acid counterpart depending on the $\mathrm{pH}$. It is mostly ionized in the buffer $(\mathrm{pH} 7)$ used to stain bacteria. Since this negative charge reduces the uptake of pro-fluorophores ${ }^{4}$, we protected the 5 -carboxylic acid moiety of carboxyfluorescein with an uncharged $n$-propyl ester (5,6-PEF, scheme 1). To investigate the influence of the 5-carboxylic acid masking group on bacteria detection, several other molecules such as the n-propyl-thiourea derivative 5-PITCF and the $n$ propylamide derivative 5-PAF were synthesized. The incorporation of fluorine atoms at positions 2' and 7' was 
also carried out (molecule 5-COGSE and its derivatives Triembarine) since fluorinated fluoresceins display better photostability and higher quantum yield ${ }^{5,6}$. In parallel to the modifications on the position 5 of carboxyfluorescein and of Oregon green (2',7' difluorocarboxyfluorescein), the hydroxyl groups at positions 3' and 6' were protected as acetates leading to 5-PEFDA, 5-PITCFDA, Triembarine DA and 5-COGDA (scheme 1). An alternative acetoxymethyl protecting group was investigated for fluorinated species because the presence of electron withdrawing fluorine atoms renders the acetate group more susceptible to spontaneous hydrolysis ${ }^{6}$. As a consequence, the acetoxymethyl group enhances stability of the profluorophore by reducing background noise.

As depicted in scheme 1, a total of 6 pro-fluorophores were thus synthesized. Their spectroscopic properties listed in supplementary table 1 show that new fluorescent probes present fluorescence characteristics similar to those of fluorescein, carboxyfluorescein, and carboxy-Oregon Green. After pro-fluorophore hydrolysis, hydrophilic products are more efficiently withheld inside cells ${ }^{4}$.

\section{Chemical stability of the pro-fluorescent probes}

To behave as convenient tools for bacteria detection, pro-fluorophores must be stable in aqueous solutions and must be efficiently activated by bacterial enzymes once they reach cell cytoplasm. We first assessed spontaneous hydrolysis by incubating compounds in labelling buffer at $37^{\circ} \mathrm{C}$ for various periods of time extending up to one hour, the selected labeling duration for bacteria revelation. As shown in Figure 1a, fluorescence intensity increases in a linear manner over the investigated period of time, with a slope reflecting the rate of profluorophore hydrolysis. As expected, the uncaging of the 3'- and 6'-hydroxyl groups was found faster for profluorophores bearing the electron-withdrawing fluorine atoms at positions 2' and 7' (5-COGDA and TriembarineDA) than the unsubstituted compounds (5-PEFDA, 5-CFDA, 5-PAFDA). As expected also, replacement of the acetate group by an acetoxymethyl (Triembarine AM) provided an approximately ten-fold improved pro-fluorophore stability in buffer (half-live of $40 \mathrm{~h}$ vs $500 \mathrm{~h}$ for Triembarine DA and Triembarine AM, respectively; figure 1a).

The stability of profluorophores was also carefully investigated in DMSO which is used for the storage of probes. The extent of product degradation was evaluated over time using liquid chromatography-mass spectrometry analysis.

After 2 months at room temperature and in the dark, $65 \%$ of Triembarine AM and $0-20 \%$ of Triembarine DA were recovered (see Figure 1b). The major side-product detected by mass was the mono-hydrolysed compounds 
(data not shown). These results show that medium-term storage ( $<2$ months) of Triembarine AM is possible if it is dissolved in anhydrous DMSO.

\section{Labeling of viable E. coli}

We next assessed the capacity of the new pro-fluorophores derived from fluorescein and Oregon Green to label E. coli cells. This was achieved by determining whether 5-PFDAE, 5-PFDAT, 5-PFDA, 5-COGDA, Triembarine DA and Triembarine AM could be recovered, as a result of bacterial endogenous esterase activity, from their corresponding pro-fluorophores. A control experiment with bacteria treated with bleach (dead bacteria) was included in the protocol to determine the specificity of the labelling process. As previous studies have established that glutaraldehyde improves the retention of CFDA in bacteria ${ }^{7}$, we incorporated $0.6 \%$ glutaraldehyde in the buffer. Bacteria (E. coli ATCC 8739) were treated for 30 min at $37{ }^{\circ} \mathrm{C}$ with profluorophore $(15 \mu \mathrm{M})$ in PBS containing glutaraldehyde $(0.6 \%)$ solution, and imaged using fluorescence microscopy. As outlined in Figure 2a, we were able to specifically stain viable E. coli with high fluorescence intensity with four esterified fluorogenic substrates (5-PAFDA, 5-COGDA, Triembarine DA and Triembarine AM). Viable E. coli treated with 5-PEFDA showed weak labeling as compared to 5-CFDA. No fluorescence signal of dead bacteria was detected. In contrast, both dead and viable E. coli became fluorescent on exposure to 5-PITCFDA, revealing that this reagent is not suitable to distinguish viable from dead E. coli. We hypothesized that the thiourea group of 5-PFDAT interacts with components of the E. coli membrane ${ }^{8-10}$ and that fluorescence probably arises from non-enzymatic hydrolysis. To quantify the labeling, bacterial fluorescence intensity was measured by spectrofluorometry (figure $2 b$ and c). Surprisingly, there was no improvement over CFDA labeling when the 5-carboxylate group was protected as a n-propyl ester (5-PEFDA) containing an ester functional group, as compared to the non-esterified 5-CFDA. On the other hand, there was significant improvement when the carboxylate moiety was protected with an amide bond such as in 5-PAFDA (2,1-2,8 fold increase over 5-CFDA; see Figure 2b). Futher introduction of fluorine atoms at positions 2' and 7'additionally increased fluorescence brightness as can be seen by comparing Triembarine DA with 5-PAFDA (2,5-3 fold increase over 5-PAFDA). This important increase in bacteria brightness is compensated for by changing the acetate into an acetoxymethyl at positions $3^{\prime}$ and $6^{\prime}$ as illustrated in Triembarine AM, resulting in a net improvement of 2,8-3,3 fold staining efficiency compared to 5-CFDA. 
The intensity of viable $E$. coli fluorescence increased when profluorophore concentrations were escalated up to a plateau value around $20 \mu \mathrm{M}$ for Triembarine precusors and close to $40 \mu \mathrm{M}$ for the other molecules 5-CFDA or 5-PAFDA (data not shown). As seen in Figure 2c, the time course of pro-fluorophore conversion to fluorophore in living $E$. coli is linear for each pro-fluorophore and variations amongst compounds are proportional throughout the 60 minutes period investigated. These results suggest that both uptake and hydrolysis rate are the basis of the differences between the tested pro-fluorophores. Experimentally, we noticed that an incubation time of $30 \mathrm{~min}$ at $37^{\circ} \mathrm{C}$ was sufficient to reliably detect, and discriminate live from dead E. coli, while keeping background noise resulting from spontaneous hydrolysis of pro-fluorophores acceptably low.

\section{Imaging bacteria with the synthesized profluorescent probes}

Esterases are present in all living organisms, and they can be used to provide information on several bacterial strains viability. To examine if the new fluorogenic esterase substrates, Triembarine DA and Triembarine AM are staining several bacterial species, waterborne bacteria were incubated with Triembarine DA, Triembarine AM or 5-CFDA $(15 \mu \mathrm{M})$ for $30 \mathrm{~min}$ at $37^{\circ} \mathrm{C}$. As shown in Supplementary figure 1 , Triembarine DA and Triembarine AM specifically stain viable, but not dead, E. cloacae, C. indologenes, P. aeruginosa (gramnegative bacteria) more intensely than 5-CFDA. They also stain viable B. subtilis (gram-positive bacteria) but with lower efficiency than 5-CFDA. Similar results were obtained with other species such as Citobacter freudii, Klebsiella oxytoca (coliform bacteria), and Chryseobacterium indologenes, Comamonas testosteroni/alcaligenes (non-coliform bacteria) (data not shown) indicating that the new pro-fluorophores (Triembarine DA and Triembarine AM) are most adequate for detecting viable gram-negative bacteria.

\section{Application of fluorescein derivative probes to detect immobilized waterborne E. coli (EC18)}

One of the current challenge in water industry is to rapidly and specifically detect viable bacteria in drinking water. Since our work shows that viable laboratory strains of E. coli are advantageously stained with Triembarine AM and Triembarine DA, we attempted to detect waterborne E. coli cells. 31 environmental isolates from the North-East region of France were acquired, grown, attenuated ${ }^{11}$ and injected as mixtures into rabbits to generate antisera. Three rounds of rabbit immunization were required to obtain polyclonal antibodies recognizing the 31 isolates. Environmental E Coli isolate 18 (EC18) was found to be the least immunogenic 
sample as it needed to be injected alone in order to get antibodies raised against it. We selected this isolate to test the robustness of the detection method.

As shown in Figure 3a, E. coli (EC18 isolate) could be visualized as red cells after incubation with rabbit antiEC18 polyclonal antibodies (anti-EC18 pAb) and revealed with AlexaFluor 568 labeled-anti rabbit immunoglobulin. These immunofluorescence images indicate that the anti-EC18 pAb reacts equally well with viable and with bleach-treated (dead) cells. The cells were in addition incubated with Triembarine DA. As shown in figure $3 \mathrm{a}$, viable, but not dead bacteria were strongly stained with green fluorescence. Anti-EC18 pAB antibodies were also used to immobilize E. coli (EC18) on beads and to concentrate the cells in order to improve detection signals. To this end, we used Protein G Sepharose beads coated with goat-anti-rabbit immunoglobulins. Immobilized bacteria were treated with 5-CFDA, Triembarine DA and Triembarine AM and imaged. Figure $3 \mathrm{~b}$ shows that green fluorescence corresponding to live bacteria is detected with all profluorophores and that intensities reached with triembarines are larger than with 5-CFDA. In addition, as shown when anti-EC18 antiserum is omitted, bacterial cells do not attach to beads with no associated non-specific labeling. These results also indicate that the uptake of 5-CFDA, Triembarine DA and Triembarine AM probes is not hindered by the presence of antibodies on the bacterial surface. Reciprocally, pro-fluorophore uptake by bacteria does not perturb the binding of antibodies to bacteria. In conclusion, Triembarine AM seems to be the best indicator because it slowly degrades spontaneously and yields high intensity labelling. All other environmental isolates were successfully immobilized with the other antisera and revealed with triembarine profluorophores (data not shown).

\section{Triembarine background extinction by different contrast agents.}

In all experiments described in figure 3, beads were washed in order to eliminate background fluorescence generated by spontaneous reagent hydrolysis. Suppression of the washing step can be achieved by using quenchers of extracellular fluorescence. Molecules that absorb light around fluorescein emission peak can be potent contrast agents if they do not penetrate into cells. Trypan blue, with maximal absorption at $580 \mathrm{~nm}$ and molar extinction coefficient $\varepsilon=50976 \mathrm{~L} \cdot \mathrm{mol}^{-1} \cdot \mathrm{cm}^{-1}$, is such a contrast agent excluded from living cells. It is however classified as a CMR compound. It is thus of limited use as a quality control reagent. Brilliant blue $\mathrm{R}^{\circledR}$ and bromophenol blue absorb light around 560-590nm (supplementary figure 2c) and do not belong to the CMR group. They have molar extinction coefficient of 43045 and $159075 \mathrm{~L}_{\mathrm{mol}}{ }^{-1} \cdot \mathrm{cm}^{-1}$ respectively at their maximal absorption wavelengths. Bacteria immobilized on beads where stained with Triembarine DA and counterstained 
with either PBS (no contrast agent), trypan blue, Brilliant blue $\mathrm{R}^{\circledR}$ or bromophenol blue (supplementary figure 2a) and the background intensity measured (supplementary figure 2b). Brilliant blue $\mathrm{R}^{\circledR}$ has the advantage to be excluded from bacteria as trypan blue (thus abolishing background) and bromophenol blue eliminates all the fluorescence. Brilliant blue R can thus be used as a contrast agent while bromophenol blue can be used to estimate the total fluorescence intensity.

These work provide a new method for bacterial staining. Specific bacteria captured on beads by specific antibodies can be stained with higher signal using the new designed pro-fluorophores Triembarine AM and DA. The background signal can be abolished by specific contrast agents (Trypan Blue ${ }^{\circledR}$, or the non CMR Brilliant $\left.b^{b l u}{ }^{\circledR}\right)$. We also described the use of the Bromophenol blue as a quencher able to penetrate gram- bacteria. This molecule can be used with automated systems for background set up between repeated measurements. 


\section{DISCUSSION}

In this work, we present several chemical modifications of the free carboxylic acid group of Oregon green and fluorescein and test them for living bacteria revelation. We obtain six new molecules with protected hydroxyl groups at positions 3' and 6' as well as masked carboxylate group at position 5. We also prepare the unprotected, fluorescent molecules and show that modifications at position 5 may modestly affect compounds brightness by reducing excitation properties and emission quantum yield by $15 \%$ at most. Therefore, the changes detected in fluorophore performances remained modest and supported further analyses such as pro-fluorphore uptake by E coli and coliform bacteria. Yet, as the introduction of two fluorine atoms at positions 2' and 7' of fluorescein were shown to improve fluorescence, we further prepared both carboxyfluorescein and Oregon green derivatives. As expected from previous reports ${ }^{5}$ we observed that diacetate of Oregon green is prone to spontaneous hydrolysis, making it necessary to prepare the more stable acetoxymethylester derivative.

\section{Protection of 5-carboxylate improves bacteria detection}

When applied to bacterial cultures, we noticed that the ester function (n-propyl ester group) used to mask the 5carboxylate (5-PEFDA) was deleterious to live bacteria detection as the fluorescence signal was smaller than that of reference compound 5-CFDA ( 0,8 fold). In contrast, we noticed that the incorporation of the n-propyl amide at the position 5 (5-PAFDA) led to significantly larger signals, indicating that an amide bond was more suitable than an ester bond to i) mask the acidic moiety of carboxyfluorescein and ii) efficiently label the live bacteria. These results clearly demonstrate the importance of the nature of the chemical bond that could influence the pro-fluorophore passive diffusion and/or alternatively the cleavage of the acetate groups to turn on the fluorescence inside the bacteria. A further improvement of fluorophore formation was observed with Triembarine protected as a di-acetate. In this case, the two fluorine atoms act as electron withdrawing groups that facilitate both acetate removal.

Modification of the 5-carboxylate of carboxyfluorescein into 5-carboxamide improves profluorophore penetration in cells

Labeling of E. coli with $n$-propyl amide of 5-carboxyfluorescein diacetate (5-PFDA) always leads to brighter fluorescence than if 5-CFDA is used instead. This reflects improved uptake of the fluorophore by bacteria. Indeed, two possibilities arise. On the one hand, both the 3' and 6' acetates and the 5-amide bond could all be cleaved, leaving 5-carboxy fluorescein as the intracellular fluorophore in both cases. This would reflect better 
uptake, since 5-PFDA-labelled cells are brighter. On the other hand, bacteria may cleave the two 3' and 6' acetates but not the 5-amide bond. This would result in cells labeled with 5-carboxy fluorescein or 5propylamido fluorescein. As $n$-propyl fluorescein has both smaller extinction coefficient and fluorescence quantum yield (supplementary table 1) than 5-carboxyfluorescein, this again supports the view that uptake is improved when the carboxylate group is masked.

\section{Contrast agents improve signal to noise ratio}

Trypan blue is generally used as a contrast agent to quench undesired fluorescence of carboxyfluorescein, in particular the fluorescence generated extracellularly by spontaneous deprotection of hydroxyl groups of carboxyfluorescein diacetate ${ }^{12}$. However, it can no longer be considered as a safe reagent since its toxicity has been established ${ }^{13}$ and has led to the classification of trypan blue as a carcinogen, mutagen and reprotoxic (CMR) molecule, in several countries. Other molecules such as brilliant blue G (Coomassie Blue) may act equally well without being classified CMR. We tested Brilliant Blue R that has appropriate spectral properties and were able to demonstrate its usefulness as a contrast agent, since it does not penetrate into live bacteria and quenches fluorescein emission efficiently at a concentration similar to that used for trypan blue. We also studied bromophenol blue and showed that this compound is a good fluorescein quencher. However, it is capable to penetrate in live bacteria, a property that can be usefully exploited for the elaboration of an automated E coli detection system. Indeed, the successive use of brilliant blue R to eradicate extracellular fluorescence, followed by the addition of bromophenol blue to all fluorescence allows the determination of specific fluorescence and to set the background signal level even if signal drifts arise in repeated equipment use.

Aggregation of bacteria improve detection sensitivity

A critical issue in assessing quality of drinking water is the sensitivity of bacteria detection. According to current regulation, one bacterium in $100 \mathrm{~mL}$ is sufficient to declare water unfit for human consumption. There is no existing method able to directly reveal the presence of a single bacterium in a $100 \mathrm{~mL}$ solution. Therefore all techniques rely on amplification (e.g. Colilert $\left.{ }^{\circledR}\right)$ and/or concentration (e.g. Colifast $\left.{ }^{\circledR}\right)$ of bacteria prior to detection. PCR techniques that can detect as few DNA as only one single cell contain, however would require massive multiplexing to cover a $100 \mathrm{~mL}$ batch $^{14,15,16,17}$. In this work, in addition to improving fluorescence brightness of labelled bacteria we attempted to improve the sensitivity of the detection by aggregating bacteria in 
a small sample volume. We succeeded in concentrating bacteria on sepharose beads to a very high density by exploiting their propensity to undergo antibody-promoted aggregation and to form deposits on sepharose beads. This also allowed washing the preparation before adding the pro-fluorophores and contrast agents and thus to optimize detection.

In conclusion, we describe here a combination of chemical modifications improving dye penetration in bacterial cells with the use of contrast agents for specific fluorescence and background signal determinations that can be operated with bacteria aggregation on beads to detect live E coli and coliform species in environment-derived samples.

Acknowledgements: The work was supported by a grant Oseo-Innovation from the french ministry of industry. CG and ES were fellows of the ministry of industry.

\section{Figure legends}

Fig. 1 Chemical stability of fluorescein derivatives.

(a) Short-term stability of pro-fluorophore in PBS solution containing $0.6 \%$ of glutaraldehyde $(\mathrm{pH} \sim 7)$. Time course experiments for the generation of fluorescence $\left(\lambda_{\mathrm{ex}}=488 \mathrm{~nm}, \lambda_{\mathrm{em}} 517 \mathrm{~nm}\right)$ of 5-CFDA, 5-PEFDA, 5PAFDA, 5-COGDA, Triembarine DA and Triembarine AM $(15 \mu \mathrm{M})$ at $37{ }^{\circ} \mathrm{C}$ in darkness. (b) Long-term stability of Triembarine DA and Triembarine AM $(120 \mu \mathrm{M})$ in DMSO at room temperature in darkness. The percentage of remaining Triembarine DA or AM was measured by monitoring the peak area on the chromatogram of HPLC-MS/MS analyses.

Fig. 2 Labeling of viable E. coli.

(a) The pictures, overlay with brightfield images, show viable or dead E. coli (ATCC 8739) incubated with different pro-fluorophores $(15 \mu \mathrm{M})$ for $30 \mathrm{~min}$ at $37^{\circ} \mathrm{C}$. Bacteria were washed before imaged with a Leica DM5500 microscope, 100x objective. Scale bars: $10 \mu \mathrm{m}$. (b) Effect of pro-fluorophore type. Viable or dead $E$. coli (ATCC 8739) were incubated with different pro-fluorophores $(10-15 \mu \mathrm{M})$ for 30 min at $37{ }^{\circ} \mathrm{C}$. After washes, E. coli fluorescence suspension was measured with FluoroLog®-3 spectrofluorometer (excitation wavelength: $488 \mathrm{~nm}$, emission wavelength: $517 \mathrm{~nm}$ ). Relative rates of viable $E$. coli fluorescence intensity were calculated as follows: (fluorescence intensity viable E. coli - fluorescence intensity dead E. coli) and normalized with 5CFDA staining. (c) Effect of incubation time. Viable E. coli (ATCC 8739) were incubated with different profluorophores $(15 \mu \mathrm{M})$ at $37^{\circ} \mathrm{C}$ for $10-60 \mathrm{~min}$. After washes, E. coli fluorescence suspension was measured with FluoroLog®)-3 spectrofluorometer (excitation wavelength: $488 \mathrm{~nm}$, emission wavelength: $517 \mathrm{~nm}$ ). 
Fig. 3 Application of new pro-fluorophore to detect immobilized environmental E. coli.

(a) Pictures show waterborne environmental E. coli (EC18) incubated with rabbit anti-EC18 polyclonal antibodies (anti-EC18 pAb) and revealed with AlexaFluor 568 labeled-anti-rabbit immunoglobulin. These treated E. coli were also incubated with Triembarine DA $(15 \mu \mathrm{M})$ for $30 \mathrm{~min}$ at $37^{\circ} \mathrm{C}$. Pictures in the left panel show the presence of antibodies at the bacterial surface (in red). Pictures in the right panel show the green fluorenscent viable E. coli stain with Triembarine DA. Bacteria were washed before imaged with a Leica DM5500 microscope, 100x objective. Scale bars: $10 \mu \mathrm{m}$. (b) Representative pictures of viable E. coli (EC18) immobilized on beads with anti-EC18 antibodies and stain with 5-CFDA, Triembarine DA or Triembarine AM $(10 \mu \mathrm{M})$ for $30 \mathrm{~min}$ at $37^{\circ} \mathrm{C}$. Pre-immune control rabbit serum without anti-EC18 antibodies (PI-pAb). After washes and trypan blue adding, beads were imaged with a Leica DM5500 microscope, 63x objective. Scale bars: $25 \mu \mathrm{m}$.

(1) Mayer, M.; Keller, A.; Szewzyk, U.; Warnecke, H.-J. J. Biotechnol. 2015, 1-6.

(2) Flemming, H. C. Appl. Microbiol. Biotechnol. 2002, 59 (6), 629-640.

(3) Pace, N. R.; Beach, M. J.; Camper, A.; Love, N.; Rose, J. B.; Stahl, D. a; Ingerson-mahar, M.; Clancy, J.; Edwards, M.; Haas, C. N.; Hernandez, M.; Roberson, A.; Burlingame, G. .

(4) Joux, F.; Lebaron, P. Microbes Infect. 2000, 2 (12), 1523-1535.

(5) Sun, W.; Gee, K. R.; Klaubert, D. H.; Haugland, R. P. 1997, 9165 (10), 6469-6475.

(6) Lavis, L. D.; Chao, T.-Y.; Raines, R. T. Chemical Science. 2011, p 521.

(7) Morono, Y.; Takano, S.; Miyanaga, K.; Tanji, Y.; Unno, H.; Hori, K. Biotechnol. Lett. 2004, 26 (5), 379-383.

(8) Barker, C. A.; Allison, S. E.; Zlitni, S.; Nguyen, N. D.; Das, R.; Melacini, G.; Capretta, A. A.; Brown, E. D. Bioorg. Med. Chem. Lett. 2013, 23 (8), 2426-2431.

(9) Limban, C.; Marutescu, L.; Chifiriuc, M. C. Molecules 2011, 16 (9), 7593-7607.

(10) Nicholson, A.; Perry, J. D.; James, A. L.; Stanforth, S. P.; Carnell, S.; Wilkinson, K.; Anjam Khan, C. M.; De Soyza, A.; Gould, F. K. Int. J. Antimicrob. Agents 2012, 39 (1), 27-32.

(11) Raghavan, S.; Hjulstro, M.; Holmgren, J.; Svennerholm, A. 2002, 70 (11), 6383-6388.

(12) Srivastava, G. K.; Reinoso, R.; Singh, A. K.; Fernandez-Bueno, I.; Hileeto, D.; Martino, M.; GarciaGutierrez, M. T.; Pigazo Merino, J. M.; Alonso, N. F.; Corell, A.; Pastor, J. C. Exp. Eye Res. 2011, 93 (6), 956-962.

(13) Awad, D.; Schrader, I.; Bartok, M.; Mohr, A.; Gabel, D. Investig. Ophthalmol. Vis. Sci. 2011, 52 (7), 4085-4090.

(14) Momtaz, H.; Dehkordi, F. S.; Rahimi, E.; Asgarifar, A. BMC Public Health 2013, 13 (1), 556.

(15) Patricia Lozano Zarain. African J. Microbiol. Res. 2012, 6 (21), 4601-4607.

(16) Janzon, A.; Sjöling, Å. ; Lothigius, Å. ; Ahmed, D.; Qadri, F.; Svennerholm, A. M. Appl. Environ. Microbiol. 2009, 75 (10), 3039-3044.

(17) Rompré, A.; Servais, P.; Baudart, J.; De-Roubin, M. R.; Laurent, P. J. Microbiol. Methods 2002, 49 (1), 31-54. 
Fig. 1 Chemical stability of fluorescein derivatives
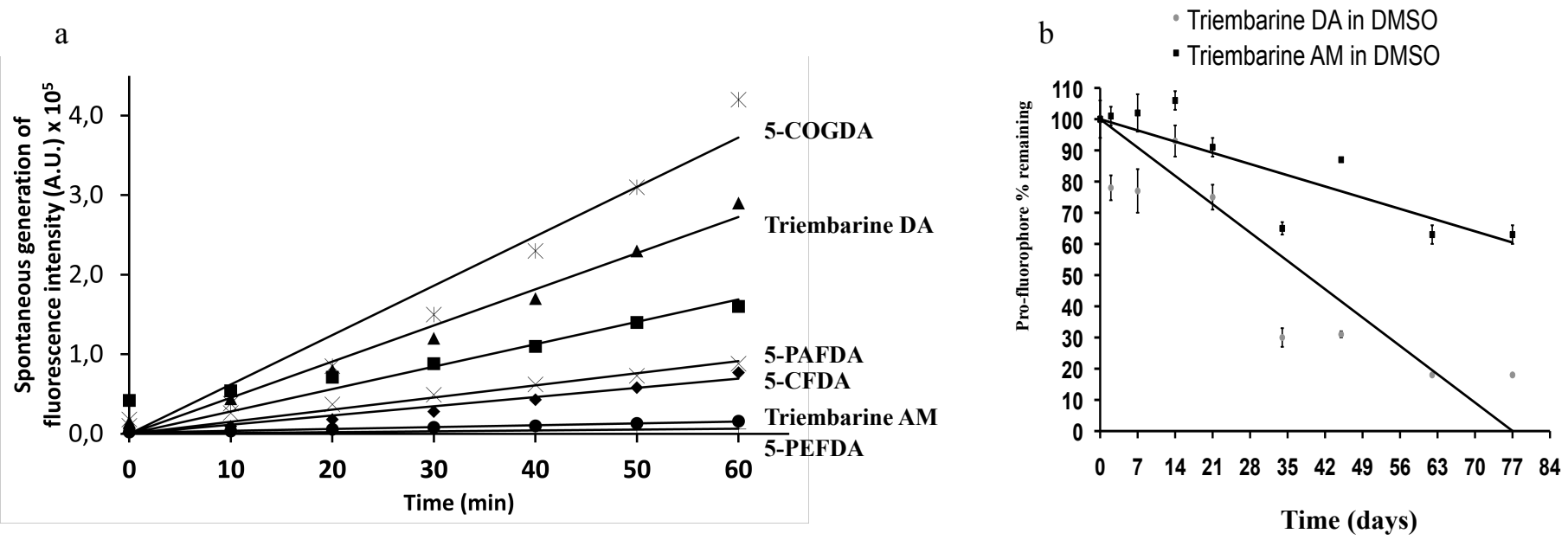
Fig. 2 Labeling of viable E. coli

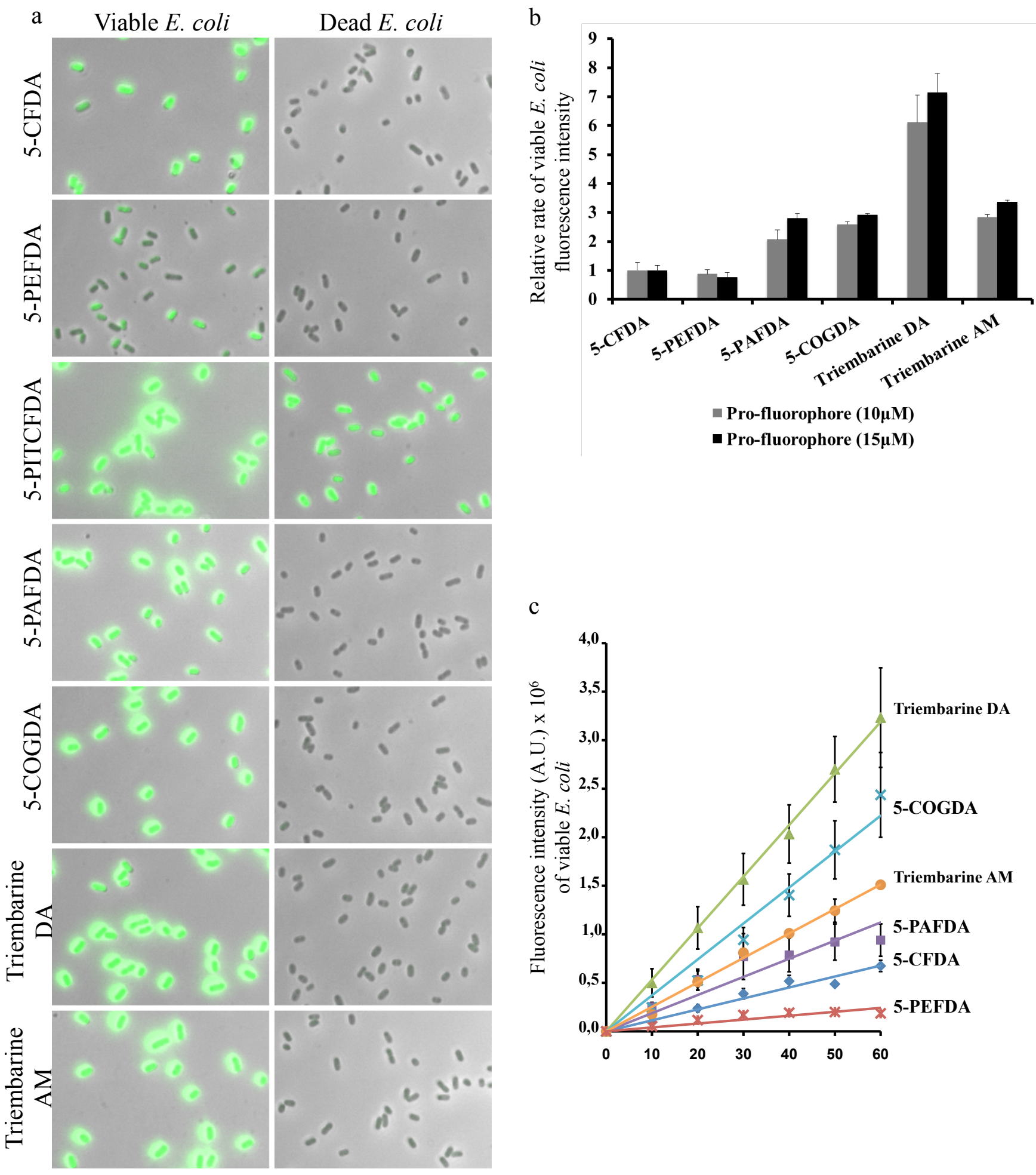


Fig. 3 Application of new pro-fluorophore to detect immobilized environmental E.coli

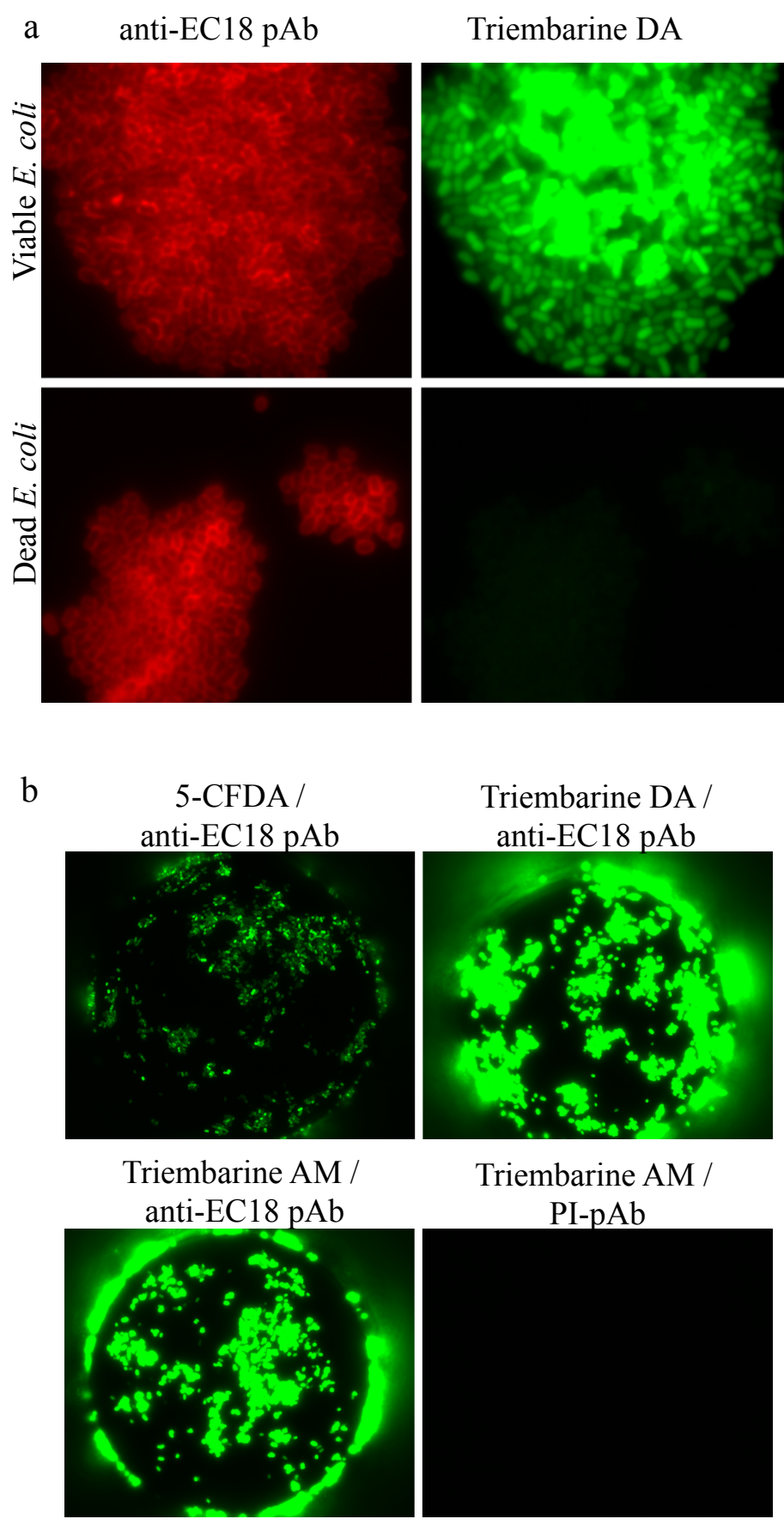

